\title{
IMPACT TOUGHNESS OF HIGH-STRENGTH LOW-ALLOY STEEL WELDED JOINTS
}

\author{
Andreja Ilić ${ }^{1}$, Lozica Ivanović ${ }^{1}$, Blaža Stojanović ${ }^{1}$, Danica Josifović ${ }^{1}$, Eleonora Desnica ${ }^{2}$ \\ ${ }^{1}$ University of Kragujevac, Faculty of Engineering, Kragujevac, Serbia \\ 2University of Novi Sad, Technical faculty “Mihajlo Pupin”, Zrenjanin, Serbia
}

\begin{abstract}
:
Impact toughness of samples with three different relative positions of $V$ notch and multipass $V$ - butt welded joint at high-strength low-alloy steel S690 are considered in this paper. The aim of this paper is to analyze the influence of material degradation due to welding to impact toughness of samples made of considered steel. Impact toughness was analyzed by experimental approach objected to including as many influential factors as it is possible. The main objective of impact toughness testing is to evaluate the influence of welding to overall load capacity and stability of welded mechanical construction made of high-strength low-alloy steels. Fully understanding of transformation processes provoked by welding of highstrength low-alloy steels and impact toughness testing as resulting property of those processes are crucial to perform integrity, safety and reliability analysis. This paper pointed out the necessity of analyzing the welded constructions on different dimension levels. Further investigations in this area have to be a continued through more quantitative analysis of welded joints which will, established precise analytical model of zones of welded joints, and furthermore, in involvement with adequate software, a complete evaluation of the experimentally obtained results. As experimentally obtained results of impact toughness that correlate to microstructure and microhardness distribution implicated that development of those steels must be followed with improving weld processes and development, adjusting and modification of the design.
\end{abstract}

\author{
ARTICLE HISTORY \\ Received 17.04.2018. \\ Accepted 02.05.2018. \\ Available 30.09.2018.
}

\section{KEYWORDS}

impact toughness, highstrength, low-alloy steel, welded joint

\section{INTRODUCTION}

Welding procedures are continually developing due to the intensive applications of the obtained results in fundamental and applied scientific disciplines to meet present demands in mechanical constructions. An ordinary welding process in present industry is based on localized heating and cooling, which creates inhomogeneous temperature fields at zones of welded joints. The consequences of applied welding technology processes are numerous and heterogeneous by its nature, such as material inhomogeneity, alteration of its chemical compositions, different microstructural transformations, etc.
On the other side, welded constructions are complex systems of heterogeneous elements with mechanical properties that are highly dependent on its welded joints. The present demands that are put on welded constructions caused significant increases in applications of high- strength low-alloy steels. Applications of those steels instead of conventional, general purpose structural steels provide many advantages. But, high-strength lowalloy steels due to specific chemical composition and microstructure are highly sensitive to influences of welding. High-strength low-alloy steels, so as considered S690QL have beneficial mechanical properties, but full benefit of applications of those steels can be obtained only 
by its adequate welding. Optimal welding technology is the main condition for preserving characteristics and microstructural state of material after welding, which are the basis of beneficial mechanical properties, and condition of joining.

High-strength low-alloy steels due to conditional weldability often require additional procedures to obtain an intended characteristic of welded joints. The processes of material degradation due to welding at those steels can be related to increasing of hardness, a decrease of toughness, an increase of transition temperature, the presence of different material discontinuities and so on. Initialization of cracks and formation of brittle structures due to welding are related to the high cooling speed of weld metal and its surrounding zone in diapason of temperature in which austenite is highly unstable. Considerations of mechanical properties of high-strength low-alloy steels must be based on its specific characteristics, as limited plasticity reserve due to high strength of steels, possible formation of local zones with lower plasticity in relation to rest of the construction and possibility of material discontinuities and initialization of cracks (primarily, hydrogen) during welding at weld metal and heat affected zone.

As material discontinues (inclusions, defects, cracks, sharp cuts, etc.) and imperfections are usually present at zones of welded joints, those zones are most dangerous from the aspect of loss of structural integrity. From the aspect of structural integrity, safety and reliability analysis, the measure the amount of energy required to cause fracture is crucial. The welded construction ability to absorb energy without compromising of integrity comes in focus of many different types of research.

Pamnani with associates in [1] evaluate the mechanical properties across the SMAW, SAW, FCAW and A-GTAW weld joints of micro-alloyed HSLA steel. The correlation between microstructure, microhardness and tensile properties obtained using automated ball indent has been undertaken.

Multi-pass submerged arc welding at highstrength low-alloy steels using multi micro-alloy electrodes with three different heat input processes was analyzed by Lan and associates in [2] to investigate the microstructure evolution and corresponding mechanical properties of weldments. The emphasis was placed on studying the influence of microstructure aspects on impact toughness of weld metal and heat affected zone (HAZ) with different heat inputs to reveal fracture micro-mechanism and to optimize the welding system.

In [3] Costa et al. present a study of the thermal behavior and its effect on phase transformations in the $H A Z$, depending on cooling rates to obtain continuous cooling transformation (CCT) curves for an high-strength low-alloy steel. The results presented in [3] showed that, with the used cooling conditions, the steel did not provide formation of brittle structures.

The results of research presented in [4] by Sadeghian et ales implicate that the results of impact tests revealed that the specimen with low heat input exhibited brittle fracture and that with high heat input had a higher strength than the base metals.

The presented results of researches in literature overview point out those properties of welded joints are a key element of structural integrity of the welded constructions. Welded structure is a complex system that can be considered from many aspects. Safety and reliability requirements for welded construction point out that welded joint zones have to be considered adequately.

The essence of determining impact toughness so as a type of fracture in zones of welded joints is the qualitative analysis of structural integrity due to the integrity of its welded joints. Capacity calculations analyze and prove mechanical resistance and stability of welded structures for the expected loads and exploitative conditions. The multiple stress concentrations at zones of welded joint and mechanical properties of welded joints are a major dominant factor to the precision of analytical models used for calculations. Data obtained from exploitation of welded constructions showed that mechanical properties of welded joints due to are nature were not adequately take in consideration in present analytical models and capacity calculations. Only results obtained by experimental testing can be taken as relevant to a high degree.

\section{EXPERIMENTAL TESTING}

The testing was done on models made of highstrength low- alloy steel S690QL, as the parent metal, commercially nominated as Weldox 700 . The used steel is produced by SSAB Oxelösund $A B$, 61380 Oxelösund, Sweden and fulfills requirement classified for EN 10025-6:2004 [5]. The chemical composition of Weldox 700 steel, according to the producer is presented in Table 1. 
Table 1. Chemical composition of Weldox 700 steel

\begin{tabular}{|c|c|c|c|}
\hline $\begin{array}{c}\text { Chemical } \\
\text { element }\end{array}$ & Content, \% & $\begin{array}{c}\text { Chemical } \\
\text { element }\end{array}$ & Content, \% \\
\hline $\mathrm{C}$ & $\max 0,20$ & $\mathrm{~V}$ & Max 0,09 \\
\hline $\mathrm{Si}$ & $\max 0,60$ & $\mathrm{Cu}$ & Max 0,30 \\
\hline $\mathrm{Mn}$ & $\max 1,6$ & $\mathrm{Ti}$ & Max 0,04 \\
\hline $\mathrm{P}$ & $\max 0,020$ & $\mathrm{Al}$ & $\begin{array}{c}\text { Total max } \\
0,015\end{array}$ \\
\hline $\mathrm{S}$ & $\max 0,010$ & $\mathrm{Mo}$ & $\operatorname{Max} 0,70$ \\
\hline $\mathrm{B}$ & $\max 0,0005$ & $\mathrm{Ni}$ & $\max 2,0$ \\
\hline $\mathrm{Nb}$ & $\max 0,04$ & $\mathrm{~N}$ & $\max 0,010$ \\
\hline $\mathrm{Cr}$ & $\max 0,07$ & & \\
\hline
\end{tabular}

Mechanical properties of considered highstrength low- alloy steel S690QL related to specific plate thickness according to producer data are min. yield strength $-\mathrm{Rp} 0,2=700 \mathrm{MPa}$; tensile strength - Rm= $780-930 \mathrm{MPa}$; elongation $A=14 \%$. The used steel is produced in two grades, nominated with suffix $E$ and $F$ in relation to impact toughness. Values of impact energy for Weldox 700 steel determined at V-notch Sharpy specimens (EN ISO 148-1:2010 and EN 10045-1:1990) are presented at Table $2[6,7]$.

Table 2. Impact energy of Weldox 700 steel

\begin{tabular}{|c|c|c|}
\hline & $\begin{array}{c}\text { Weldox } 700 E \\
\text { at }-40^{\circ} \mathrm{C}\end{array}$ & $\begin{array}{c}\text { Weldox } 700 \mathrm{~F} \\
\text { at }-60^{\circ} \mathrm{C}\end{array}$ \\
\hline Min. impact energy & $69 \mathrm{~J}$ & $27 \mathrm{~J}$ \\
\hline $\begin{array}{c}\text { Nom. according to } \\
\text { EN 10025-6:2004 }\end{array}$ & S690QL & S690QL1 \\
\hline
\end{tabular}

Butt V-joint is done by welding at plates with a thickness of $15 \mathrm{~mm}$. Microphotography of cross sections of considered welding joints after metallographic preparation and chemical etching by $4 \%$ nitric acid in alcohol is presented in Fig.1.

a)

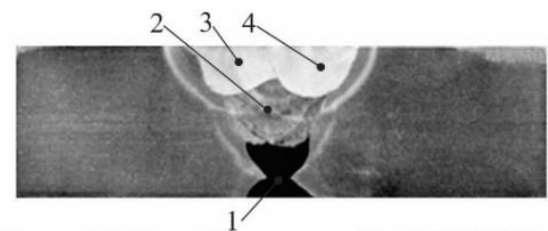

1- rooth pass $M M A$, welding consumable INOX 18/8/6

2, 3, 4, 2' $, 3^{\prime}, 4^{\prime}$ - other passes $M A G$, welding consumables $M I G 75$

Fig. 1. Microphotography of cross-sections of considered welded joint

The root pass is done by MMA welding process and welding consumables with a lower strength (pass - 1), while other passes are done by MAG welding process and welding consumables with higher strength (passes - 2, 3 and 4). Welding parameters for each pass and mechanical characteristics of related welding consumables are presented in Table 3.

Table 3. Welding parameters and mechanical characteristics of related welding consumables

\begin{tabular}{|c|c|c|c|}
\hline \multicolumn{2}{|c|}{ Parameter } & Root pass $M M A$ & $\begin{array}{l}\text { Root pass } \\
\text { MIG }\end{array}$ \\
\hline \multicolumn{2}{|c|}{ Current, $I_{z}$} & $\approx 120 \mathrm{~A}$ & $\approx 110 \mathrm{~A}$ \\
\hline \multicolumn{2}{|c|}{ Voltage, $U$} & $\approx 24 \mathrm{~V}$ & $\approx 24 \mathrm{~V}$ \\
\hline \multicolumn{2}{|c|}{$\begin{array}{l}\text { Welding speed, } \\
\qquad v_{z}\end{array}$} & $\approx 0.2 \mathrm{~cm} / \mathrm{s}$ & $\approx 0.35 \mathrm{~cm} / \mathrm{s}$ \\
\hline \multicolumn{2}{|c|}{ Heat input, $q_{l}$} & $\approx 12 \mathrm{~kJ} / \mathrm{cm}$ & $\approx 13 \mathrm{~kJ} / \mathrm{cm}$ \\
\hline \multicolumn{2}{|c|}{ Penetration, $\delta$} & $\approx 1.8 \mathrm{~mm}$ & $\approx 1.8 \mathrm{~mm}$ \\
\hline \multicolumn{2}{|c|}{$\begin{array}{l}\text { Protective } \\
\text { atmosphere }\end{array}$} & - & $\begin{array}{c}100 \% \mathrm{Ar} \\
(\mathrm{M} 11)\end{array}$ \\
\hline \multicolumn{2}{|c|}{$\begin{array}{c}\text { Welding } \\
\text { consumables }\end{array}$} & $\begin{array}{c}\text { INOX } \\
B \text { 18/8/6; } \\
\varnothing 3.25 \mathrm{~mm}\end{array}$ & $\begin{array}{c}\text { MIG 18/8/6 Si; } \\
\quad \varnothing 1.2 \mathrm{~mm}\end{array}$ \\
\hline \multirow{4}{*}{ 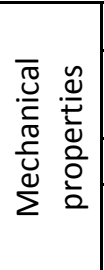 } & $\mathrm{R}_{\mathrm{m}}, M P a$ & $590-690$ & $560-660$ \\
\hline & $\begin{array}{l}\mathrm{R}_{\mathrm{p} 0.2} \\
\mathrm{MPa}\end{array}$ & $>350$ & $>380$ \\
\hline & $A_{5}, \%$ & $>40$ & $>35$ \\
\hline & $\mathrm{KV}, \mathrm{J}$ & $\begin{array}{c}>80 \\
(+20 \circ C)\end{array}$ & $\begin{array}{c}>40 \\
(+20 \circ C)\end{array}$ \\
\hline
\end{tabular}

Charpy V-notched samples are prepared according to related standards and norms. The preparation of samples is done with minimal additional heat input. The Charpy method of impact toughness test is a standardized high strainrate test for determination of the energy absorbed by a sample to fracture. The standard dimensions of the sample for Charpy impact toughness test are presented in Fig.2.

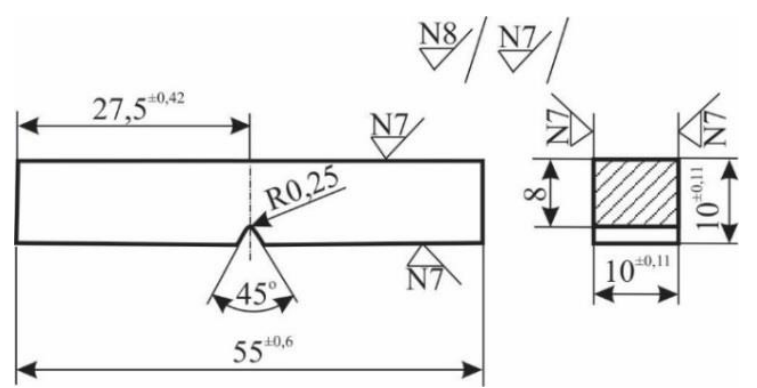

Fig. 2. Standard sample for Charpy impact testing

As the zone of welded joint is indicated as critical from the aspect of material degradation $\mathrm{V}$ notch is done at its specific zones; weld metal, fusion zone, and heat affected zone. The method of the preparation of samples from the aspect of the relative positioning of $\mathrm{V}$-notch and welded joint is presented in Fig.3. Preparing of samples is done with special care in order to avoid additional heat input, corrosion and other types of material degradation. Visualization of welded joins is done 
by metallurgical preparation in order to obtain specific relative position between welded joint and $\mathrm{V}$-notch. Testing procedure was design and done in order to obtained relevant tasting data related to current industrial practice and usual exploitative conditions. Impact toughness is a very important mechanical characteristic of the material that can be defined as a measure of the energy need to be absorbed to cause fracture of the sample or the compromise the integrity of the structure of materials. When this energy is less material having a higher brittleness, and when this energy is greater material having a higher toughness.

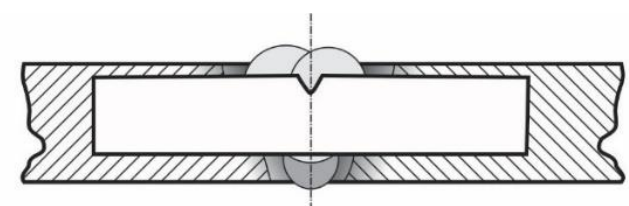

V-notch at weld metal toward face of welded joint

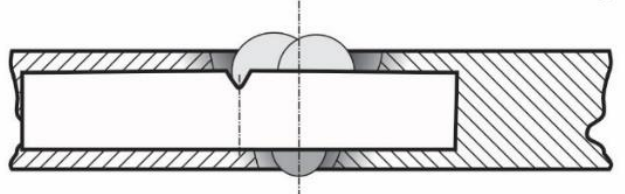

V-notch at fusion zone toward face of welded joint

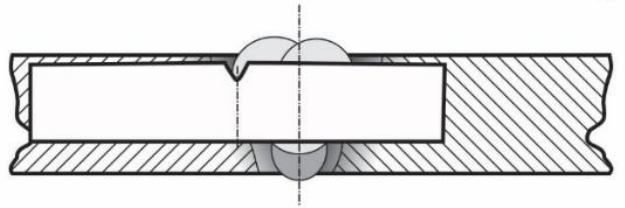

V-notch at HAZ toward face of welded joint

Fig. 3. Positions of $\mathrm{V}$-notch for preparation of samples for impact toughness testing

The appearance of prepared samples after preparation for metallurgical preparation and chemical etching by $4 \%$ nitric acid in alcohol before testing are presented in Fig.4. The metallurgical preparation and chemical etching were done in order to visualize specific zones of welded joint.

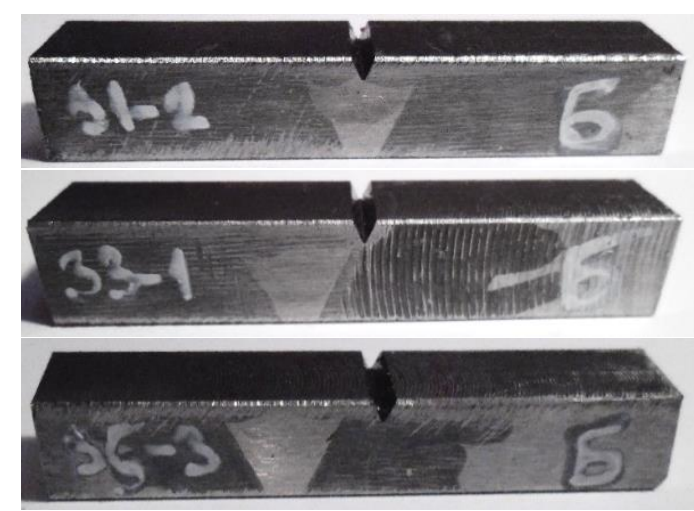

Fig.4. Charpy V-notched samples
Testing was done using a pre-defined standardized procedure on a series of samples for each position of V-notch at a temperature of $20^{\circ} \mathrm{C}$. Testing machine is based on the computerized Charpy pendulum, presented at Fig. 5 .

The used computerized Charpy pendulum is a device for measuring the energy absorbed by the samples to a fracture, which is a measure of toughness. The test procedure, the shape, and dimensions of the samples are defined by the standard EN ISO 148-1: 2010 and EN 10045-1: 1990 - Metallic materials - Test impact strength Charpy impact, i.e. SRPS EN ISO 148-1 : 2012. Speed pendulum during impact strength test is from 5 to $5.5 \mathrm{~m} / \mathrm{s}$, while the energy losses are less than $1 \%$.

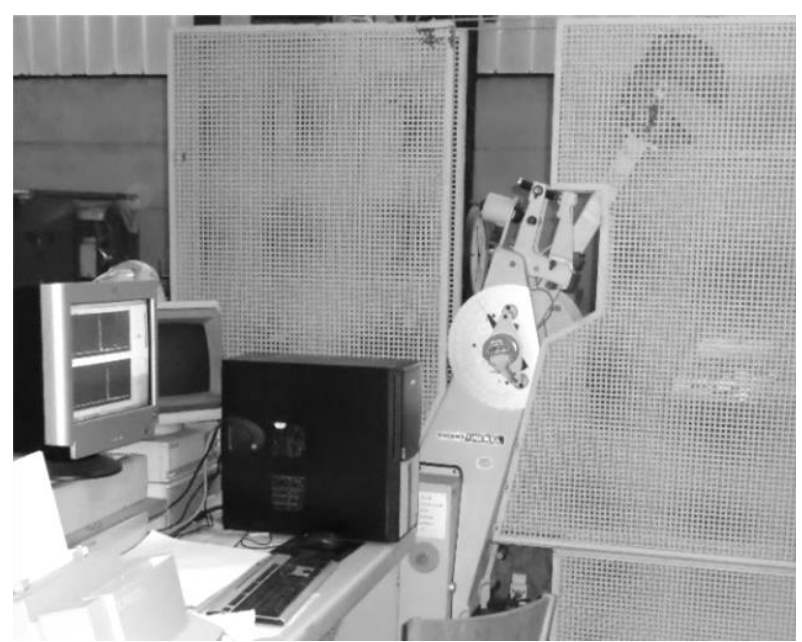

Fig. 5. Computerized Charpy pendulum used for testing

The force and energy during testing of impact toughness were registered. The obtained results show very small relative exceptions and can be taken as relevant for further analysis.

\section{TESTING RESULTS}

The experimentally obtained values of fracture energy and force - time depending during the fracture of the tested samples show very small mutual deviations and consistent behavior so the results can be taken as relevant for further consideration. Experimental results indicate a mixed character of fracture of the tested samples. Force-time dependence to fracture during impact toughness testing of samples with $V$-notch at weld metal from the face of welded joint is presented in Fig.6. 


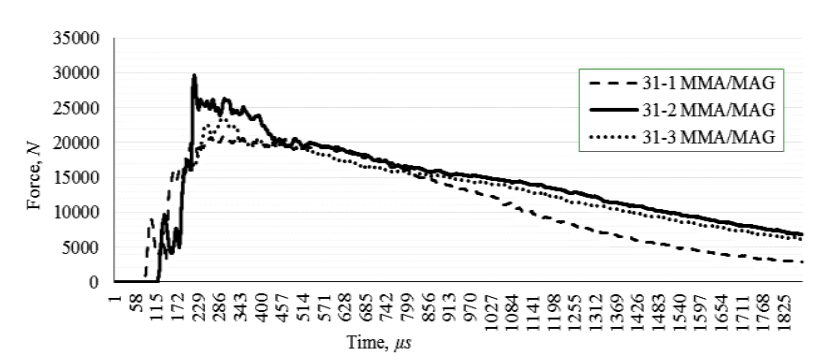

Fig. 6. Force-time dependence to fracture during impact toughness testing

The changing of the absorbed energy to fracture for the sample with V-notch at weld metal from the face of welded joint at testing temperature is shown diagrammatically in Fig.7.

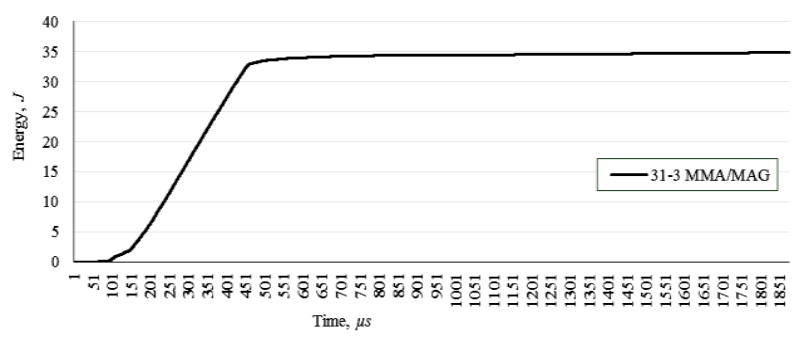

Fig. 7. Changing of energy to fracture during testing for samples with $\mathrm{V}$-notch at weld metal

The appearance of sample with V-notch in welded joint after testing is presented in Fig.8. The appearance of the surface created by fracture indicates its mixed character means both brittle and ductile fracture. The appearance of the fracture surfaces is in accordance with certain mechanical characteristics during testing impact toughness and character of force-time and energytime relations. The test procedure is then done at specimens notched in the fusion zone, as at the test samples with the notch in the heat affected zone towards face of the welded joint.

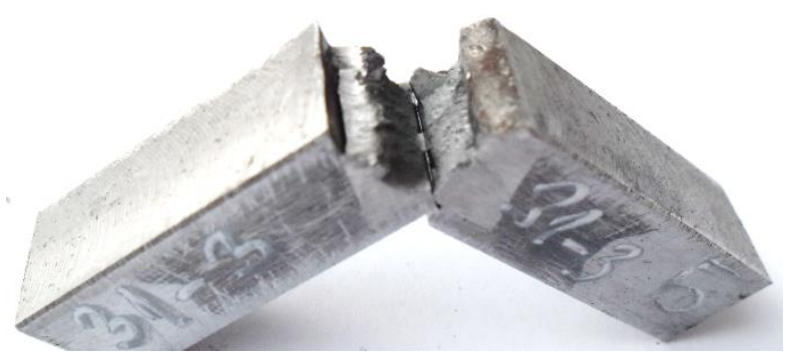

Fig. 8. Sample with $\mathrm{V}$-notch at welded joint after testing of impact toughness

Force-time dependence to fracture during impact toughness testing of samples with V-notch at fusion zone from the face of welded joint is presented in Fig.9.

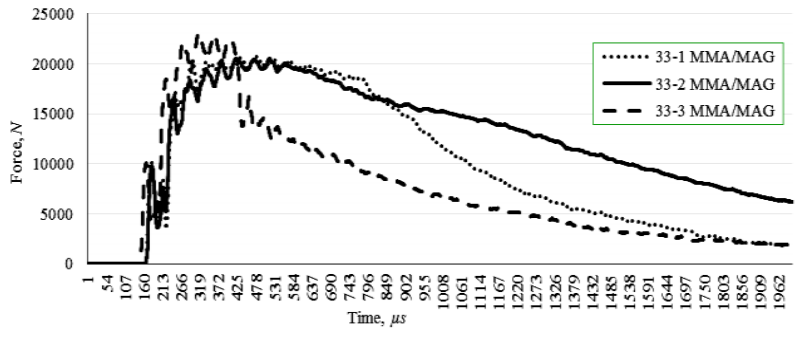

Fig. 9. Force-time dependence to fracture during impact toughness testing

The changing of the absorbed energy to fracture for the sample with V-notch at fusion zone from the face of welded joint at testing temperature is shown diagrammatically in Fig.10.

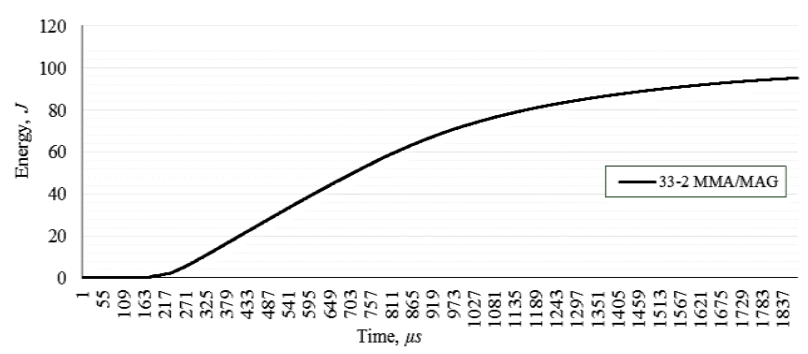

Fig. 10. Changing of energy to fracture during testing for samples with V-notch at fusion zone

Force-time dependence to fracture during impact toughness testing of samples with V-notch at HAZ from the face of welded joint is presented in Fig.11.

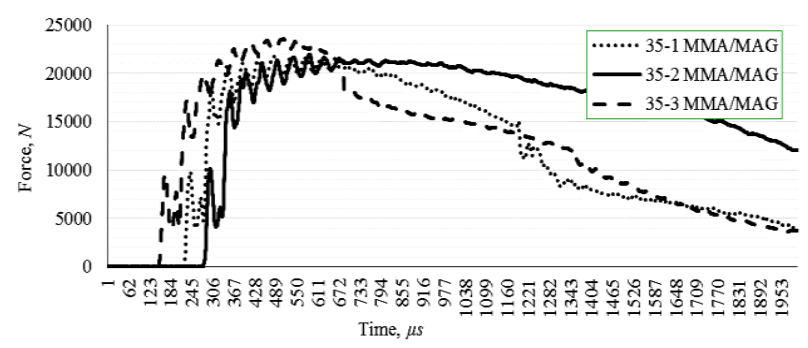

Fig. 11. Force-time dependence to fracture during impact toughness testing

The changing of the absorbed energy to fracture for the sample with V-notch at HAZ from the face of welded joint at testing temperature is shown diagrammatically in Fig.12.

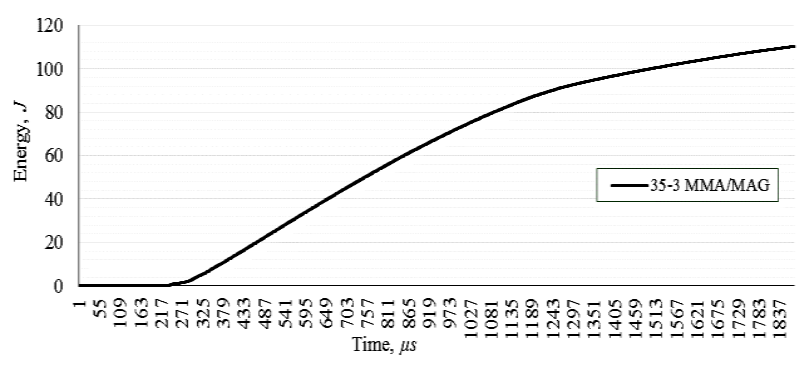

Fig. 12. Changing of energy to fracture during testing for samples with V-notch at HAZ 
Experimentally determined values of fracture energy have small mutual deviation, the relations force - time show the same character, so testing results can be taken as relevant for further analysis. The histogram presented in Fig.13 show experimentally obtained fracture energy for samples with different positions of $V$-notch towards to weld face.

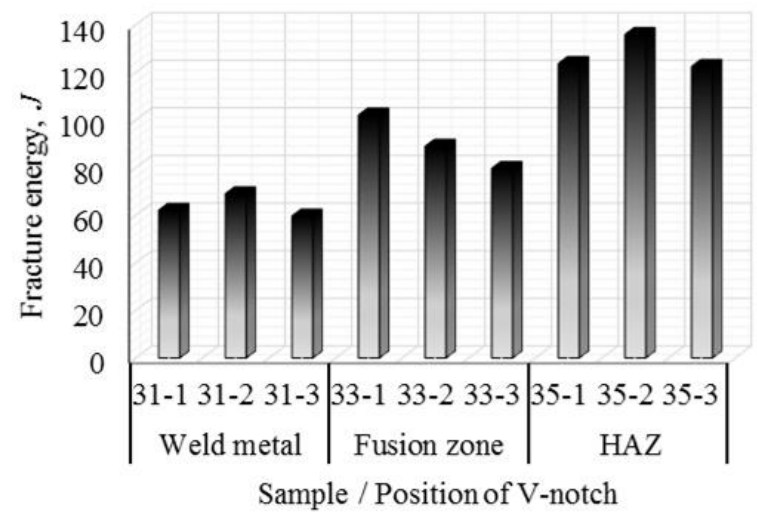

Fig. 13. Fracture energy of tested samples

\section{EVALUATION OF THE OBTAINED RESULTS}

Experimentally obtained the value of energy that is absorbed to fracture for different positions of V-notch toward to the face of welded joint it can be concluded that the maximal energy is obtained for samples with the V-notch in the heat affected zone, while slightly less for samples with the Vnotch at fusion zone. The lowest values of absorbed energy were obtained for samples with a notch at the axis of weld metal. The experimentally obtained values of energy are lower than at control samples made of parent material without welded joint. The appearance of the fracture surface for samples notched in the fusion zone toward the face of the welded joints after impact toughness testing at room temperature is presented in Fig.14.

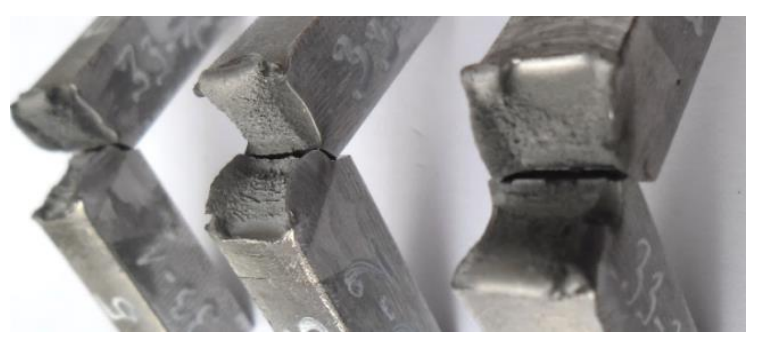

Fig. 14. Appearance of fracture surface after testing of samples notched at fusion zone

The appearance of the fracture surface shows a mixed character of fracture with distinct zones of brittle and ductile fracture. The appearance of the fracture surface for samples notched at the heat affected zone toward the face of the welded joints after impact toughness testing at room temperature is shown in Fig.15.

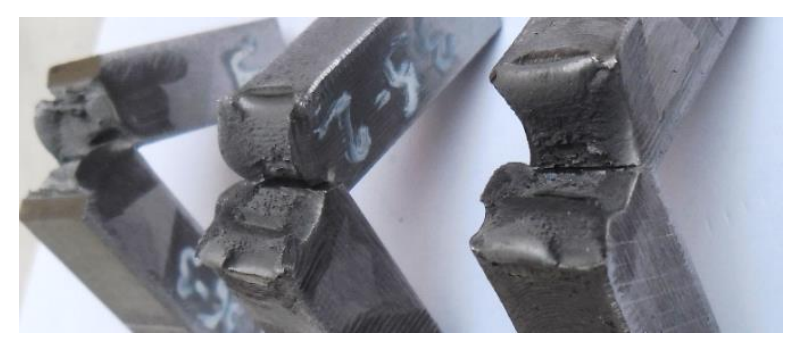

Fig. 15. Appearance of fracture surface after testing of samples notched in $\mathrm{HAZ}$

On fracture surface differ brittle and ductile fracture zone, indicating a mixed fracture character of tested sample, which is in agreement with the experimental values of impact strength and theoretical considerations related to this area.

\section{CONCLUSION}

Due to welding microstructural state at heat affected zone will be transformed in relation to the chemical composition of parent and filler metal, thermal cycles due to welding etc. High heat input affected the growth of metal grain that means degradation of strength and toughness, while low heat input during welding caused low penetration of fusion zone. As chemical compositions and microstructural state are complex altogether with high sensitivity to heat input, producers of those steels provide recommendations for filler metal and preheating temperatures, limitations for heat input and interpass temperatures [8-10].

Present norms, standards, and recommendations for the design of welding joints at high-strength low-alloy steels are based on heterogeneous backgrounds. Also, limitations are established for different reasons in order to provide welded joint with adequate mechanical properties. On the other side, methods for improving the impact toughness and load capacity of welded joints to forming of defect and inclusions are based, primarily, on relaxing residual stress state, reducing hydrogen content and obtaining preferred thermal cycles during welding and cooling. Due to the complexity of factors and their interactions, present standards and recommendations are still not fully developed and precise, especially related to effects of specific welding parameters to chemical compositions and microstructural state at specific zones of welding 
joints and by that to impact toughness as complex general characteristic caused by a large number of factors. From the practical aspect and obtaining relevant data for design optimization, mechanical characteristics, and properties, stability and integrity analyses of welded joints at this steel grade is crucial. Due to complex nature of welded joints, only experimental testing can provide relevant data and information about the mechanical behavior of welded joints at high strength low alloyed steels during exploitation.

\section{ACKNOWLEDGMENT}

This paper is a result of the research activities conducted under the project "Sustainable development of technology and equipment for motor vehicles recycling" TR 35033, which is financed by the Ministry of Education, Science and Technological Development of Republic of Serbia.

\section{REFERENCES}

[1] R. Pamnani, V. Karthik, T. Jayakumar, M. Vasudevan, T. Sakthivel, Evaluation of mechanical properties across micro alloyed HSLA steel weld joints using Automated Ball Indentation. Materials Science and Engineering: A, 651 (-), 2016: 214-223.

https://doi.org/10.1016/j.msea.2015.10.104

[2] L. Lan, X. Kong, C. Qiu, D. Zhao, Influence of microstructural aspects on impact toughness of multi-pass submerged arc welded HSLA steel joints. Materials \& Design, 90 (-), 2016: 488-498.

https://doi.org/10.1016/j.matdes.2015.10.158

[3] P.S. Costa, F.A. Reyes-Valdés, R. SaldañaGarcés, E.R. Delgado, A. Salinas-Rodríguez, Thermal Behavior of an HSLA Steel and the Impact in Phase Transformation: Submerged
Arc Welding (SAW) Process Approach to Pipelines. Characterization of Metals and Alloys, 2017: 85-98.

https://doi.org/10.1007/978-3-319-31694-9 7

[4] M. Sadeghian, M. Shamanian, A. Shafyei, Effect of heat input on microstructure and mechanical properties of dissimilar joints between super duplex stainless steel and high strength low alloy steel. Materials \& Design, $60(-), 2014:$ 678-684.

http://dx.doi.org/10.1016/j.matdes.2014.03.057

[5] EN 10025-6:2004 - Technical delivery conditions for flat products of high yield strength structural steels in the quenched and tempered condition

[6] ISO 148-1:2009 - Metallic materials - Charpy pendulum impact test - Part 1: Test method

[7] EN 10045-1:1990 - Metallic materials - Charpy impact test - Part 1: Test method

[8] A. Ilić, Influence of shape complexity, material, stress concentration and temperature to design of welded constructions, (Ph.D. Thesis). Faculty of Mechanical Engineering, University of Kragujevac, Kragujevac, 2015.

[9] A. Ilić, L. Ivanović, B. Rakić, D. Josifović, V. Lazić, Influence of welding technology to mechanical properties of welding joints at high strength low alloy steels, The $8^{\text {th }}$ International Symposium KOD 2014, Machine and Industrial Design in Mechanical Engineering, 12-15 June, 2014, Balatonfüred, Hungary, pp.255-260.

[10] V. Lazić, S. Aleksandrović, D. Arsić, A. Sedmak, A. Ilić., M. Đorđević, L. Ivanović, The influence of temperature on mechanical properties of the base material and welded joint made of steel S690QL. Metalurgija, 55 (2), 2016: 213216. 